\title{
Article
}

\section{Evaluation of an educational intervention that aims to improve the keep/refer decision-making abilities of Austrian undergraduate physiotherapy students: a randomised pilot study}

Lackenbauer, Wolfgang, Janssen, Jessie, Roddam, Hazel and Selfe, James

Available at http://clok.uclan.ac.uk/33315/

Lackenbauer, Wolfgang, Janssen, Jessie, Roddam, Hazel ORCID: 0000-00020637-1801 and Selfe, James (2020) Evaluation of an educational intervention that aims to improve the keep/refer decision-making abilities of Austrian undergraduate physiotherapy students: a randomised pilot study.

International Journal of Therapy and Rehabilitation, 27 (5). ISSN 1741-1645

It is advisable to refer to the publisher's version if you intend to cite from the work. $10.12968 / \mathrm{ijtr} .2019 .0001$

For more information about UCLan's research in this area go to http://www.uclan.ac.uk/researchgroups/ and search for <name of research Group>.

For information about Research generally at UCLan please go to http://www.uclan.ac.uk/research/

All outputs in CLoK are protected by Intellectual Property Rights law, including Copyright law. Copyright, IPR and Moral Rights for the works on this site are retained by the individual authors and/or other copyright owners. Terms and conditions for use of this material are defined in the policies page. 


\section{Evaluation of the feasibility, acceptability and potential effectiveness of an educational intervention which aims to improve the keep/refer decisions making abilities of Austrian undergraduate physiotherapy students: A randomised pilot study.}

Lackenbauer $\mathrm{W}<1,2>$ Janssen $\mathrm{J}<2>$ Roddam $\mathrm{H}<3>$ Selfe $\mathrm{J}<1>$.

1 Manchester Metropolitan University, Department of Health Professions, Manchester, United Kingdom.

2 University of Applied Sciences Krems, Department of Health Sciences, Krems, Austria.

3 University of central Lancashire, School of Health Sciences, Lancashire, United Kingdom.

\section{Abstract \\ Background/Aims}

An ongoing discussion about direct access to physiotherapy for patients with musculoskeletal pain disorders in Austria requires the development of a curriculum that educates physiotherapy students to make autonomous keep/refer decisions and to recognise the presence of serious pathologies.

Methods

This randomised pilot study examined the feasibility, acceptability and potential effectiveness of an educational intervention which aimed to improve the keep/refer decision making competencies of Austrian sixth semester undergraduate physiotherapy students.

Findings

Half of Austrian universities $(n=6 / 12)$ and 116 final year Austrian undergraduate physiotherapy students took part in the study. All students from the intervention group were 
satisfied with the intervention and $77.6 \%$ found the intervention beneficial for making keep/refer decisions based on clinical vignettes. $89.7 \%$ did not find the intervention too time consuming. A potential effectiveness of the intervention could not be demonstrated.

Conclusions

Future similar studies need to investigate if more teaching hours and/or if different educational methods are capable of improving the keep/refer decision making abilities of Austrian undergraduate physiotherapy students.

\section{Introduction}

Musculoskeletal (MSK) pain has become a major health problem and substantial socioeconomic burden around the globe (Slater and Briggs 2017). One strategy to cut down the staggering financial pressure on health care systems due to MSK pain disorders is the creation of a direct access system to a wider pool of health professions (e.g. to physiotherapy) without the need for prior medical evaluation and/or referral (Marks et al. 2017). Proponents of direct access to physiotherapy argue that there is an associated decline in waiting times for patients (Ojha et al. 2014), a decrease in the workload for doctors (Leemrijse et al. 2008) and a high level of patients' satisfaction when being examined by a primary care physiotherapist (Samsson and Larsson 2014). The preeminent argument of opponents to a direct access system to physiotherapy is that physiotherapists lack formal training to recognise the presence of serious pathologies which require the attention of a physician (Crout et al. 1998; Deyle 2006; Jette et al. 2006; Leemrijse et al. 2008; Piano et al. 2017).

\section{The physiotherapists' and physiotherapy students' ability to recognise serious pathologies}

In recent years, studies have revealed limitations of qualified physiotherapists in the United States (Riddle et al. 2004; Ladeira 2018), Germany (Beyerlein 2010), Switzerland (Nast et al. 2013), Doctor of Physical Therapy (DPT) students in the United States (Vaughn et al. 2011) 
and of European final year undergraduate physiotherapy students (Lackenbauer et al. 2018; Klein et al. 2018) to accurately identify serious medical conditions which require immediate medical attention based on clinical vignettes. Results by Lackenbauer et al. (2018) and Klein et al. (2018) however revealed that study participants from the Netherlands were more accurate in identifying serious pathologies which require immediate medical attention based on clinical vignettes as compared to German physiotherapy students (Klein et al. 2018) and to physiotherapy students from nine other European countries (including students from Austria) (Lackenbauer et al. 2018). The ability of Dutch physiotherapy students to recognise the presence of serious pathologies is not without reason as the Dutch professional physiotherapy guidelines clearly demand that physiotherapists know when a referral to another health care professional (e.g. a physician) is required (Lackenbauer et al. 2017; Klein et al. 2018).

\section{Physiotherapy education in a changing practice environment}

While some European countries already have direct access to physiotherapy (e.g. Finland, Sweden, the Netherlands, the United Kingdom), there is the desire from other national physiotherapy associations including Germany (Konrad and Geraedts 2018), Belgium (ERWCPT 2018) and Austria (Sorge 2017) to implement a direct access system to physiotherapy. The discussion about direct access to physiotherapy in Austria has more recently led to amendments in the mandatory learning outcomes within the Austrian undergraduate physiotherapy curriculum (Eckler et al., 2017). In the case of direct access to physiotherapy in Austria, it will be then paramount for new graduates to independently screen patients for the presence of serious pathology which requires medical evaluation and/or treatment (Eckler et al. 2017). These amendments (Eckler et al. 2017) now urgently warrant the development of a curriculum that properly educates Austrian undergraduate physiotherapy students to make accurate clinical decisions as to whether a patient is suitable for physiotherapy (keep) or needs the attention of a physician (refer). However, before being included into the existing Austrian 
undergraduate curriculum, educational strategies need to be tested for their ability to teach Austrian physiotherapy students how to make sound keep/refer decisions and, most importantly, to recognise the presence of serious medical conditions.

\section{Educational methods within healthcare education}

Although it is acknowledged that a wide range of different educational methods exist, three main teaching methods are commonly discussed within the health care education literature (Srinivasan et al. 2007; Tärnvik 2007; Nelson 2010; Lowe 2011):

- The lecture-based format.

- The case-based method (CBL).

- The problem-based method (PBL).

The lecture-based format includes passive acquisition of information which is then subsequently assessed by the amount of information that has been stored by the student (Lowe 2011). Lowe (2011) criticises that the lecture-based format does not examine whether students are able to put the acquired information into use in the clinical, real world setting or context (Lowe, 2011). As opposed to the lecture-based format, PBL and CBL have been introduced. Both approaches foster good clinical reasoning and decision making competencies within health care and medical education (Nelson 2010). Tärnvik (2007) describes that "PBL stimulates students to explore the knowledge needed to understand a given phenomenon, whereas the case method offers opportunities for familiarization and deepening of knowledge already acquired through lectures and other sources" (Tärnvik 2007, p. 33). Although it is still unclear which teaching method produces the better clinicians (Thistlewhaite et al. 2012), a benefit of CBL over PBL is that CBL is less time consuming and possibly more suitable for less experienced learners (Srinivasan et al. 2007).

\section{Feasibility and pilot studies}


The development of complex interventions is suggested to follow the Medical Research Council (MRC) framework for the development and evaluation of randomised controlled trials (RCTs) for complex interventions to improve health (MRC 2000). A special form of complex interventions is educational interventions "targeted on the health professional" (MRC 2000: p. 2). To assess whether a future definitive RCT is feasible, multiple feasibility and pilot studies are expected to be carried out prior to a definitive RCT (MRC 2000). The primary objective(s) of feasibility and pilot studies is to test the workability of a future definitive RCT (Eldridge et al. 2016). A definitive RCT will then eventually primarily assess the efficacy/effectiveness of an intervention (Eldridge et al. 2016).

\section{Study objectives and study design}

The feasibility, acceptability and potential effectiveness of a CBL educational intervention to improve the keep/refer decision making abilities and recognition rates of serious pathologies of Austrian undergraduate physiotherapy students has not been assessed.

In order to fill this research gap, a randomised pilot study was carried out. This randomised pilot study was conducted in accordance with the CONSORT 2010 statement extension to randomised pilot and feasibility studies (Eldridge et al. 2016).

\section{Methods}

\section{Participants, setting and timescales}

The recruitment process started in November 2017 and ended in June 2018. To obtain a homogenous sample, this study targeted final year undergraduate physiotherapy students in Austria. The study was carried out as close as possible to the end of the third (final) year. As directly recruiting the students was not feasible (due to the issue of data protection), the lead author contacted heads of the 12 physiotherapy schools in Austria via telephone and e-mail in autumn 2017. These 12 universities had a total of 469 final year undergraduate physiotherapy students. Seven physiotherapy schools showed a high level of interest in this study. These 
seven universities had a total of 310 final year undergraduate physiotherapy students.

Subsequently, a date convenient for participating universities was arranged. The implementation of the educational intervention and data collection was conducted between February 2018 and June 2018 at the sites of individual universities in Austria. Whilst participation of the students remained voluntary, the heads of physiotherapy schools were asked to promote the study by distributing an information sheet among the target population several weeks before the execution of the study. Interested students were then asked to show up on the (with individual universities') agreed date. After a brief oral description of the study protocol by the lead author in person, written consent from the students present was obtained. No incentives to participate were provided.

\section{Randomisation}

The random allocation procedure was conducted identically at each participating university and was administered and monitored by the lead author: Volunteering students were randomly allocated to the intervention or control group by drawing slips of paper without replacement out of a non-transparent bag. Half of the students were then led into a separate room. Students from both groups were only then told which group they had been assigned to. The separate room was necessary to separate the control from the intervention group. This separation was crucial so that students from the control group could not take part in the educational intervention which was exclusively provided to students from the intervention group.

\section{Intervention}

The description of the educational intervention followed (where applicable) the guideline for reporting evidence-based practice educational interventions and teaching (GREET) (Phillips et al 2016). The educational intervention consisted of a single, one hour face-to-face CBL lecture on the principles of differential diagnosis, screening for possible red flag pathologies 
and review of the body systems (Boissonnault and Bass Part I-III 1990; Henschke et al. 2013; Williams et al. 2013). To avoid any potential errors in the students' understanding as a result of language, the content of all research material was summarized and presented by the lead author in German. The CBL lecture was administered at each participating university exclusively by the lead author who has a six year experience of teaching in a CBL format as a lecturer at a University of Applied Sciences. The control group did not receive an active intervention.

\section{Materials and procedure}

To assess the keep/refer decision making competencies of students from both groups, a survey containing 11 validated vignettes (Mount 2012) was used. Clinical vignettes are generally recognised as reliable and valid tools for measuring clinical decision making competencies of health professionals (Peabody et al. 2000; Peabody et al. 2004) and have been widely used in the past to assess clinical decision making competencies of qualified physiotherapists (Riddle et al. 2004; Jette et al. 2006; Beyerlein 2010; Mount 2012; Nast et al. 2013; Ladeira 2018) and physiotherapy students (Vaughn et al. 2011; Lackenbauer et al. 2018; Klein et al. 2018). Students from the intervention group were asked to complete the 11 vignettes immediately after the educational intervention under the supervision of the lead author. Students from the control group completed the 11 cases immediately following the random allocation process in a separate room under the supervision of an administrator from the university. Only one keep/refer answer option per vignette was possible. In accordance with others (Jette et al. 2006; Beyerlein 2010; Nast et al. 2013; Vaughn et al. 2011; Mount 2012; Lackenbauer et al. 2018; Klein et al. 2018), individual case contents of the 11 vignettes were classified as:

- Musculoskeletal.

- Medical non-critical. 
- Medical critical.

Replicating previously used methodology (Jette et al. 2006; Beyerlein 2010; Vaughn et al. 2011; Mount 2012; Nast et al. 2013; Lackenbauer et al. 2018; Klein et al. 2018), a correct answer for the musculoskeletal cases was to treat the patient without the need for medical referral (keep) or to treat the patient with additional medical check-up (keep and refer). A correct answer for the medical non-critical cases was defined if the student(s) chose to start physiotherapy with additional medical evaluation (keep and refer) or refer the patient without physiotherapeutic management (refer). The sole correct answer for medical critical cases was the decision to send the patient for medical evaluation without physiotherapeutic management (refer).

Also in accordance with previous research (Beyerlein 2010; Lackenbauer et al. 2018), students were given a time limit (14 minutes) to complete the 11 vignettes. A time limit for the completion of the 11 vignettes was set to simulate clinical decisions which are made under time pressure (Veloski et al. 2005). The 14 minutes for the 11 vignettes in the current study were calculated based on previous research by Beyerlein (2010) and Lackenbauer et al. (2018). Beyerlein (2010) and Lackenbauer et al. (2018) gave 15 minutes for the completion of 12 vignettes which equals 75 seconds for each vignette. Replicating these numbers as closely as possible, students from the current study sample were given 14 minutes for the completion of 11 vignettes.

Students from the intervention group were also asked to fill out a supplementary questionnaire following the completion of the 11 clinical vignettes. This questionnaire contained three questions which were used to rate the acceptability of the CBL educational intervention from the perspective of students from the intervention group. Due to the lack of availability of identical survey instruments, this questionnaire was developed as a bespoke instrument for the purposes of this randomised pilot study (Appendix 1). The acceptability of the CBL 
educational intervention was assessed by following the theoretical framework of acceptability (TFA) by Sekhon et al. (2017) in terms of affective attitude ('were you generally satisfied with the intervention?'), burden ('do you feel that the intervention was too time consuming?') and perceived effectiveness ('do you personally feel that the additional lecture was helpful for you to make an accurate keep/refer decision based on the 11 vignettes?'). No time limit was set for the completion of the supplementary questionnaire.

\section{Outcomes}

The primary outcomes were feasibility, acceptability and potential effectiveness and are listed below:

The feasibility of a future RCT was analysed in terms of absolute recruitment rates for students. A recruitment threshold of at least 74 students was determined to indicate the feasibility of a future definitive RCT in relation to recruitment. This was based on using data from an earlier non-randomised-pilot study (unpublished data) and the results from a cross sectional study among European undergraduate physiotherapy students (including students from Austria) (Lackenbauer et al. 2018). A sample size of 37 students in each group was calculated to have $90 \%$ power for a future RCT to detect a difference in correct keep/refer decisions for the medical critical vignettes in means of $20 \%$ (mean for the control group: $46 \%$; mean for the intervention group: $66 \%$ ) assuming that the common standard deviation was $26 \%$ using an unpaired t-test with an alpha level of $5 \%$ (two-sided).

In line with Diamond et al. (2014), a threshold for acceptability in terms of affective attitude, burden and perceived effectiveness of the educational intervention was set to $75 \%$ of the students from the intervention group. 
The detection of serious medical pathologies, which require medical evaluation, is a key component of an ongoing discussion about increased practice autonomy for physiotherapists in Austria. The focus of the educational intervention was therefore on teaching students how to recognize the presence of serious medical conditions which require a referral to a physician. Hence, it was assumed that students from the intervention group would make on average more accurate answers for the medical critical cases.

\section{Analytical section}

Data analysis was carried out using the Statistical Package for Social Sciences (SPSS) for windows version 22.0.0.2 (IBM, USA).

Recruitment rates were analysed using raw counts (percentages and numbers) of participating universities and students in relation to the target population.

As questions about the acceptability of the educational intervention were closed-ended items (categorical data), the frequencies of responses were presented in raw counts (percentages and numbers) of the study sample.

Measurements of central tendency (mean and median) and variability (standard deviation and percentiles) of correct responses for musculoskeletal, medical non-critical and medical critical cases for both the control and intervention group were calculated. In addition, percentages of students from both the intervention and control group who made a correct keep/refer decision for $100 \%$ of the musculoskeletal, medical non-critical and medical critical cases were also analysed.

\section{Ethical approval}

Ethical approval 1390 was obtained from Manchester Metropolitan University Faculty of Health, Psychology and Social Care Ethics Committee. Heads of physiotherapy schools in 
Austria were explicitly asked about the need for additional local ethical approval but it was confirmed that ethical approval from the lead author's host institutions of Manchester Metropolitan University and from the University of Central Lancashire was sufficient.

\section{Results}

\section{Feasibility}

Heads of physiotherapy undergraduate programmes from seven universities in Austria (58.3\%) initially agreed to take part in the pilot study and distributed a description of the study protocol among their final year undergraduate physiotherapy students. The final number of six participating Austrian universities represented 50\% of all universities in Austria which provide a bachelor degree in physiotherapy. The final study sample consisted of a convenience sample of 116 sixth semester undergraduate physiotherapy students i.e. - $24.7 \%$ of the target population.

Flow diagram should be inserted approximately here.

\section{Acceptability}

All participants from the intervention group (100\%) were satisfied with the intervention (affective attitude). $77.6 \%(n=45)$ of the participants from the intervention group reported the lecture to be helpful for completing the 11 vignettes (perceived effectiveness). $89.7 \%(\mathrm{n}=52)$ of participants from the intervention group did not deem the intervention too time consuming (burden).

\section{Potential effectiveness of the CBL educational intervention}

All 116 participants (100\%) completed the 11 clinical vignettes. Consequently, all 116 surveys were included in the data analysis. Comparison of the mean and median percentages of accurate keep/refer decisions for the musculoskeletal, medical non-critical and medical 
critical vignettes revealed minor differences between the intervention and control group. A correct keep/refer decision for the medical critical vignettes was made on average in slightly more than half of the cases by both groups. Very few participants from both groups managed to make an accurate keep/refer decision for all four vignettes from the medical critical category.

Table 1 and 2 should be inserted approximately here.

\section{Discussion}

This was the first study to examine the feasibility, acceptability and potential effectiveness of a one hour, CBL educational intervention which aimed to improve the keep/refer decision making competencies of Austrian undergraduate physiotherapy students. Half of Austrian universities $(n=6 / 12)$ and 116 final year Austrian undergraduate physiotherapy students took part in the study. $100 \%$ of students from the intervention group were satisfied with the intervention (affective attitude) and $77.6 \%$ reported the intervention to be beneficial for making keep/refer decisions based on clinical vignettes (perceived effectiveness). $89.7 \%$ did not find the intervention too time consuming (burden). The potential effectiveness of a single hour CBL educational intervention could however not be demonstrated.

The high level of the students' satisfaction with an educational intervention based on the CBL approach adopted within the current study is in line with previous reports which have also demonstrated a generally positive attitude towards the CBL method in health care education (Nelson 2010).

The importance of qualified physiotherapists and physiotherapy students learning how to independently recognize the presence of serious pathologies has repeatedly been in the focus of a discussion within the Austrian health care system (Sorge 2017). There is an ongoing desire from the Austrian national physiotherapy association to implement a direct access 
system to physiotherapy. This has resulted in amendments to learning outcomes for undergraduate physiotherapy studies across Austria (Eckler et al. 2017). In the case of direct access to physiotherapy in Austria, it will be then paramount for new graduates to independently screen patients for the presence of serious pathology which require medical attention. These amendments (Eckler et al. 2017) pose a significant challenge and this was probably a major reason for the high level of interest from Austrian physiotherapy schools and Austrian final year undergraduate physiotherapy students in this randomised pilot study. Due to the fact that the participation rate exceeded the pre-specified minimum of 74 students, the feasibility in terms of recruitment rates of a future RCT is likely.

When working in a direct access setting, it is crucial to recognise the presence of serious pathologies which are not suitable for physiotherapy but require immediate referral for medical evaluation. Hence, another objective of this randomised pilot study was to observe a potential effectiveness of the CBL educational intervention. Yet, the results from this randomised pilot study failed to demonstrate a potential effectiveness of a single hour CBL educational intervention. One reason for the failed potential effectiveness of the CBL educational intervention possibly was due to its duration. Unfortunately, time constraints from the side of Austrian universities and students at the end of semester six dictated that this randomised pilot study had to be conducted with only one lecture per university and without a follow-up period. Yet, a failed potential effectiveness of the current intervention could also potentially relate to the educational method employed. A systematic review by Thistlethwhaite et al. (2012) showed that CBL is widely recognised as an effective teaching method for educating health professionals. In addition, a benefit of CBL over PBL is that $\mathrm{CBL}$ is less time consuming and possibly more suitable for less experienced learners (Srinivasan et al. 2007). On the other hand, Thistlethwaite et al. (2012) pointed out that there 
is still inconclusive evidence whether CBL is more effective in producing better clinicians than other learning types.

In the end, students from both groups made on average a correct keep/refer decision in about $50 \%$ of the cases from the medical critical category (table 1). In addition, only very few students managed to answer all four medical critical cases correctly (table 2). On the other hand, students had a high level of accuracy for vignettes from the musculoskeletal and medical non-critical category (table 1 and 2). Consequently, students within the current study sample did not overestimate but underestimated the possibility of serious pathologies within clinical vignettes. The weakness to identify serious pathologies based on clinical vignettes is in line with previous reports on qualified physiotherapists in the United States (Riddle et al. 2004; Ladeira 2018), Germany (Beyerlein 2010), Switzerland (Nast et al. 2013), Doctor of Physical Therapy (DPT) students in the United States (Vaughn et al. 2011) and on European final year undergraduate physiotherapy students (Lackenbauer et al. 2018; Klein et al. 2018). The inability to recognise the presence of serious pathologies is especially problematic as the preeminent argument of opponents to a direct access system to physiotherapy is that physiotherapists lack formal training to recognise the presence of serious pathologies which require the attention of a physician (Crout et al. 1998 DA general file; Deyle 2006; Jette et al. 2006; Leemrijse et al. 2008; Piano et al. 2017).

\section{Limitations}

Due to the lack of funding, the translation of the 11 vignettes into German had to be solely done by the lead author and did not follow the guidelines for the comprehensive process of cross-cultural adaption of self-report measures described by Beaton et al. (2000). Furthermore, as blinding of study participants and research personnel was ultimately infeasible for the current study, performance bias could not be prevented. As only the experimental group received some educational information (intervention), experimental bias 
(Hawthorne effect) could not be ruled out (Portney and Watkins 2009). Furthermore, time constraints from the side of Austrian universities and students at the end of semester six caused for this randomised pilot study to be conducted with only one lecture per university and without a follow-up period. Yet, the study protocol (one lecture with subsequent written exam) was still in accordance with previous research by Boissonnault et al. (2006). Another important issue applies to non-response bias. Students from all volunteering universities were given preliminary information about this study. It was therefore likely that only students took part that were generally interested in the topic of this pilot study and also felt comfortable with the completion of clinical vignettes. Some authors have also condemned the uncritical application of clinical vignettes in health care related research (Veloski et al. 2005; Mohan et al. 2014). Veloski et al. (2005) argued that the answers given by clinicians within clinical vignettes may tend to represent rather idealistic responses and not necessarily the most realistic ones (social desirability bias). The issue of social desirability bias has been further substantiated by Mohan et al. (2014). Their results revealed poor correlation between transfer decisions based on hypothetical cases (vignettes) as compared to real trauma patients in an emergency department (Mohan et al. 2014).

Finally, the generally poorer results for the medical critical vignettes (table 1 and 2) might be explained by the fact that only one answer option (refer) was considered correct. On the other hand, two different keep/refer options for the vignettes of the musculoskeletal (keep or keep/refer) and medical non-critical category (keep/refer or refer) were accurate. Whilst this is acknowledged, the possibility of coming across potential medical emergencies justifies a rigorous approach without any other options for the treating physiotherapist (Lackenbauer et al. 2018).

\section{Conclusion}


A single-hour CBL educational intervention which aimed to improve the keep/refer decision making abilities of Austrian undergraduate physiotherapy students was found to be feasible and acceptable. A potential effectiveness of the CBL educational intervention could, however, not be demonstrated. Participants from the intervention group did not make on average more accurate keep/refer decisions for the medical critical vignettes than participants from the control group. This pre-specified criterion was therefore not fulfilled. Consequently, the progression towards a definitive RCT with the primary aim to assess the efficacy of this single hour, CBL educational intervention is not recommended. Before the progression towards a definitive RCT can be recommended, future studies need to determine the optimal amount of teaching hours needed to improve the keep/refer decision making competencies and especially the recognitions rates of serious pathologies of undergraduate physiotherapy students in Austria. It remains unclear which teaching methods produce the better clinicians.

Consequently, instead of using a control group, future similar studies might compare different teaching approaches or methods, for example lecture-based versus PBL versus CBL.

National physiotherapy associations that seek direct access to physiotherapy in their countries are well advised to put effort into the development of evidence based educational strategies which have been shown to successfully teach students how to make accurate keep/refer decisions and to recognise serious pathologies with precision. Otherwise, the main argument of the opponents to physiotherapists working as primary care clinicians (that physiotherapists are incapable of recognising serious pathologies) cannot be refuted.

\section{Key points:}

- It was feasible to recruit sufficient physiotherapy students for a single hour CBL intervention. 
- Students from the intervention group found a single hour CBL intervention which aimed to improve the keep/refer decision making abilities acceptable.

- A one hour CBL intervention did not improve the recognition rates of serious pathologies based on clinical vignettes.

- Future similar studies should assess whether greater contact and teaching hours improve the keep/refer decision making skills.

- Future studies could compare different teaching approaches/methods to assess their impact on keep/refer decision making abilities.

\section{Reference list}

1. Beaton DE, Bombardier C, Guillemin F, Ferraz MB. 2000. Guidelines for the Process of Cross-Cultural Adaption of Self-Report Measures. Spine (Phila Pa 1976). 25(24):3186-3191.

2. Beyerlein C. 2010. Direktzugang in der Physiotherapie - Wie entscheiden sich Physiotherapeuten im Management ihrer Patienten [dissertation]. Universitätsklinikum Ulm. 80 p.

3. Boissonnault W, Morgan B, Buelow J. 2006. A Comparison of Two Strategies for Teaching Medical Screening and Patient Referral In a Physical Therapist Professional Degree Program. Phys Ther Educ. 20(1):28-36.

4. Boissonnault WG, Bass C. 1990. Pathological origins of trunk and neck pain: part Ipelvic and abdominal visceral disorders. J Orthop Sports Phys Ther. 12(5):192-207.

5. Boissonnault WG, Bass C. 1990. Pathological Origins of Trunk and Neck Pain: Part II - Disorders of the Cardiovascular and Pulmonary System. J Orthop Sports Phys Ther. 12(5):208-215.

6. Boissonnault WG, Bass C. 1990. Pathological Origins of Trunk and Neck Pain: Part III - Diseases of the Musculoskeletal System. J Orthop Sports Phys Ther. 12(5):216221.

7. Crout KL, Tweedie JH, Miller DJ. 1988. Physical Therapists' Opinions and Practices Regarding Direct Access. Phys Ther. 78(1):52-61 
8. Deyle GD. 2006. Direct access to physical therapy and diagnostic responsibility: the risk-to-benefit ratio. J Orthop sporty Phys Ther. 36(9):632-634.

9. Diamond IR, Grant RC, Feldman BM, et al. 2014. Defining consensus: a systematic review recommends methodological criteria for reporting of Delphi studies. J Clin Epidemiol. 67(4):401-409.

10. Eckler U, Gödl-Purrer B, Hurkmans E, Igelsböck E, Wiederin C. Kompetenzprofil [Internet]. 2017. PhysioAustria; [cited 2018 Dec 20]. Available from: https://www.physioaustria.at/system/files/general/phy_kompetenzprofil_deutsch_fin_ 072017.pdf

11. Eldridge SM, Chan CL, Campbell MJ, et al. 2016. CONSORT 2010 statement: extension to randomised pilot and feasibility trials. Pilot Feasibility Stud [Internet]. [cited 15 Dec 2018];2(64):1-32. Available from: https://www.bmj.com/content/bmj/355/bmj.i5239.full.pdf

12. erwcpt.eu. Belgium. [Internet]. 2018. European Region World Confederation for Physical Therapy; [cited 2018 Dec 20]. Available from: https://www.erwcpt.eu/about_er-wcpt/member_organisation/6-axxon-physicaltherapy-in-belgium

13. Henschke N, Maher CG, Ostelo RWJG, de Vet HC, Macaskill P, Irwig L. 2013. Red flags to screen for malignancy in patients with low-back pain. Cochrane Database Syst Rev [Internet]. [cited 5 Dec 2018]2: 1-29. Available from: https://www.cochranelibrary.com/cdsr/doi/10.1002/14651858.CD008686.pub2/epdf/f ull

14. Jette DU, Ardleigh K, Chandler K, McShea L. 2006. Decision-Making Ability of Physical Therapists: Physical Therapy Intervention or Medical Referral. Phys Ther. 86(12):1619-1629.

15. Klein P, Rottler E, von Wietersheim J. 2018. Screening in Physiotherapy. Differences in the Skills of Participants of Different Training Courses in Germany and the Netherlands. Physioscience. 10(4):170-177.

16. Konrad R, Geraedts M. 2018. Case-oriented selection of investigation methods in direct access: A comparison between physiotherapy trainees at professional colleges and in bachelor's study courses. GMS J Med Educ [Internet]. [cited 5 Dec 2018] 35(1):1-22. Available from: https://www.ncbi.nlm.nih.gov/pmc/articles/PMC5827191/pdf/JME-35-10.pdf

17. Lackenbauer W, Janssen J, Roddam H, Selfe S. 2017. Is keep/refer decsion making an integral part of national guidelines for the physiotherapy profession within Europe? A review. Physiotherapy. 103(4):352-360.

18. Lackenbauer W, Janssen J, Roddam H, Selfe S. 2018. Keep/refer decision making abilities of European final year undergraduate physiotherapy students: a crosssectional survey using clinical vignettes. Europ J Phys Ther. 20(3):128-134.

19. Ladeira CE. 2018. Physical Therapy clinical specialisation and management of red and yellow flags in patients with low back pain in the United States. J Man Manip Ther. 26(2):66-77.

20. Leemrijse CJ, Swinkels ICS, Veenhof C. 2008. Direct Access to Physical Therapy in the Netherlands: Results From the First Year in Community-Based Physical Therapy. Phys Ther. 88(8):936-946.

21. Lowe W. (2011. Is the Sun Setting on Lecture-Based Education? Int J Ther Massage Bodywork. 4(4): 7-9.

22. Marks D, Comans T, Bisset L, Scuffham PA. 2017. Substitution of doctors with physiotherapists in the management of common musculoskeletal disorders: a systematic review. Physiother. 103(4):341-351. 
23. Medical Research Council (MRC). (2000). A FRAMEWORK FOR DEVELOPMENT AND EVALUATION OF RCTS FOR COMPLEX INTERVENTION TO IMPROVE HEALTH. London: MRC. [accessed 2017 December 8]:[19 p.] https://mrc.ukri.org/documents/pdf/rcts-for-complex-interventions-to-improve-health/

24. Mohan D, Fischhoff B, Farris C, et al. 2014. Validating a vignette-based instrument to study physician decision making in trauma triage. Med Decis Making. 34(2):242-252.

25. Mount HE. 2012. SCREENING FOR MEDICAL REFERRAL: DETERMINING VARIABLES THAT INFLUENCE ACCURACY [dissertation]. University of Alabama. 28 p. Available from: http://www.mhsl.uab.edu/dt/2014r/Mount_uab_0005D_10713.pdf

26. Nast I, Allet L, Bürge E, Schermesser M, Stegen C, Schämann A. 2013. Direct Access to Physiotherapy: How Do Swiss Physiotherapists Decide on Further Procedures in First Contact? Physioscience. 9(4):153-160.

27. Neslon TK. 2010. Case-Based Learning (CBL) in Selected Physical Therapy Curricula and Its Perceived Effectiveness by Students, Faculty, and Administrators [dissertation] University of New Orleans. 200 p. Available from: https://scholarworks.uno.edu/cgi/viewcontent.cgi?article=2143\&context=td

28. Ojha HA, Snyder RS, Davenport TE. 2014. Direct access compared with referred physical therapy episodes of care: a systematic review. Phys Ther. 94(1):14-30.

29. Peabody JW, Luck J, Glassman P, Dresselhaus TR, Lee M. 2000. Comparison of Vignettes, Standardized Patients, and Chart Abstraction: A Prospective Validation Study of 3 Methods for Measuring Quality. JAMA. 283(13): 1715-1722.

30. Peabody JW, Luck J, Glassman P, Jain S, Hansen J, Spell M, Lee M. 2004. Measuring the Quality of Physician Practice by Using Clinical Vignettes: A Prospective Validation Study. Ann Intern Med. 141(10): 771-780.

31. Phillips AC, Lewis LK, McEvoy MP, et al. 2016. Development and validation of the guideline for reporting evidence-based practice educational interventions and teaching (GREET). BMC Med Educ [Internet]. [cited 5 Nov 2018];16(237):1-10. Available from: https://bmcmededuc.biomedcentral.com/articles/10.1186/s12909-016-0759-1

32. Piano L, Maselli F, Viceconti A, Gianola S, Ciuro A. 2017. Direct access to physical therapy for the patient with musculoskeletal disorders, a literature review. J Phys Ther Sci. 29(8):1463-1471.

33. Portney LG, Watkins MP. 2009. Foundations of Clinical Research: Application to Practice. Upper Saddle River (NJ): Pearson Education.

34. Riddle LD, Hillner BE, Wells PS, Johnson RE, Hoffman HJ, Zuelzer WA (2004) Diagnosis of Lower- Extremity Deep Vein Thrombosis in Outpatients with Musculoskeletal Disorders: A National Survey Study of Physical Therapists. Phys Ther 84(8):717-28.

35. Samsson K, Larsson MEH. 2014. Physiotherapy screening of patients referred for orthopaedic consultation in primary care - A randomised controlled trial. Man Ther. 19(5):386-391.

36. Sekhon M, Cartwright M, Francis JJ. 2017. Acceptability of healthcare interventions: an overview of reviews and development of a theoretical framework. BMC Health Serv Res [Internet]. [cited 12 Oct 2018]; 17(88):1-13. Available from: https://www.ncbi.nlm.nih.gov/pmc/articles/PMC5267473/pdf/12913_2017_Article_20 31.pdf

37. Slater S, Briggs AM. 2017. Models of Care for musculoskeletal pain conditions: driving change to improve outcomes. Pain Manag. 7(5):351-357. 
38. Sorge M. 2017. Ihre Meinung und weitere Schritte zum Direktzugang. Inform. 5:8-9.

39. Srinivasan M, Wilkes M, Stevenson F, Nguyen T, Slavin S. 2007. Comparing Problem-Based Learning with Case-Based Learning: Effects of a Major Curricular Shift at Two Institutions. Acad Med. 82(1): 74-82.

40. Tärnvik A. 2007. Revival of the case method: a way to retain student-centred learning in a post-PBL era. Med Teach. [accessed 2018 February 2]:[5 p.] DOI: 10.1080/01421590601039968.

41.Thistlethwhaite JE, Davies D, Ekeocha S, Kidd JM, MacDougall C, Matthews P, Purkis J, Clay D. 2012. The effectiveness of case-based learning in health professional education. A BEME systematic review: BEME Guide No. 23. Med Teach. [accessed 2018 February 10]:[23 p.] DOI: 10.3109/0142159X.2012.680939.

42. Vaughn DW, Shoemaker MJ, DaPrato D, Murray KS, Van Huisen J. 2011. The Ability of Final-Year Doctor of Physical Therapy Students to Make Keep/Refer Decisions. J Phys Ther Educ. 25(3):60-67.

43. Veloski J, Tai S, Evans AS, Nash DB. 2005. Clinical Vignette-Based Surveys: A Tool for Assessing Physician Practice Variations. Am J Med Qual. 20(3):151-157.

44. Williams CM, Henschke N, Maher CG, et al (2013) Red flags to screen for vertebral fracture in patients presenting with low-back pain. Cochrane Database Syst Rev [Internet]. [cited 10 Dec 2018]; 1:1-38. Available from:

https://www.cochranelibrary.com/cdsr/doi/10.1002/14651858.CD008643.pub2/full\#0 


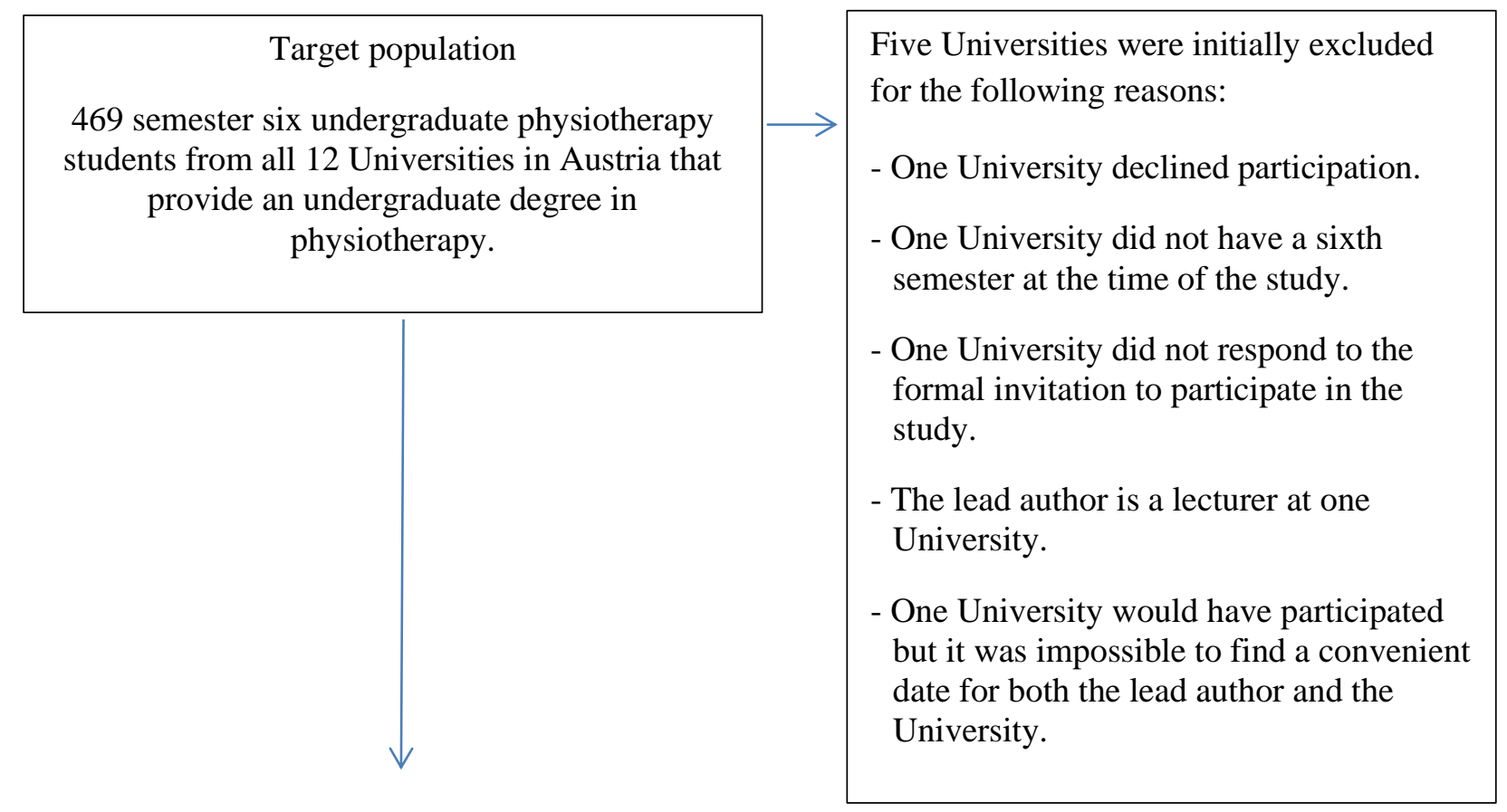

119 semester six undergraduate physiotherapy students from 6 Universities in Austria were randomly assigned into either an intervention or control group.

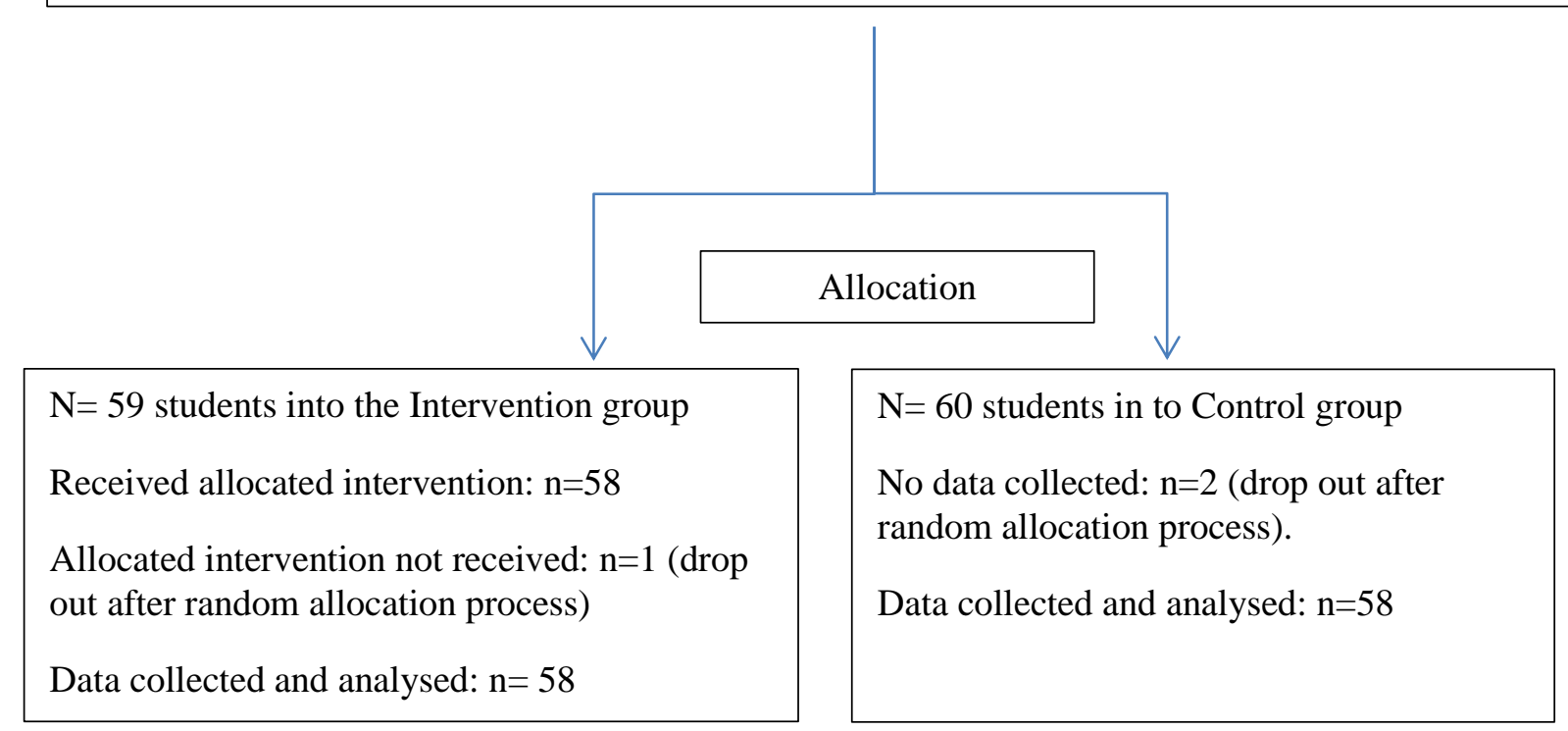

Flow diagram for the randomised pilot study. 
Table 1: Mean and median percentages of correct keep/refer decisions for the musculoskeletal, medical non-critical and medical critical vignettes for the intervention and control group.

\begin{tabular}{|c|c|c|c|c|c|}
\hline & & & Musculoskeletal & $\begin{array}{c}\text { Medical non } \\
\text { critical }\end{array}$ & $\begin{array}{l}\text { Medical } \\
\text { critical }\end{array}$ \\
\hline \multirow{5}{*}{ Intervention group } & \multicolumn{2}{|l|}{ Mean } & $97.1 \%$ & $93.5 \%$ & $52.6 \%$ \\
\hline & \multicolumn{2}{|l|}{ Median } & $100 \%$ & $100 \%$ & $50 \%$ \\
\hline & \multicolumn{2}{|l|}{ Std. Deviation } & $9.4 \%$ & $11.9 \%$ & $15.3 \%$ \\
\hline & \multirow{2}{*}{ Percentiles } & 25 & $100 \%$ & $93.8 \%$ & $50 \%$ \\
\hline & & 75 & $100 \%$ & $100 \%$ & $50 \%$ \\
\hline \multirow{5}{*}{ Control group } & \multicolumn{2}{|l|}{ Mean } & $99.4 \%$ & $88.8 \%$ & $53.4 \%$ \\
\hline & \multicolumn{2}{|l|}{ Median } & $100 \%$ & $100 \%$ & $50 \%$ \\
\hline & \multicolumn{2}{|l|}{ Std. Deviation } & $4.3 \%$ & $16.9 \%$ & $21.7 \%$ \\
\hline & \multirow{2}{*}{ Percentiles } & 25 & $100 \%$ & $75 \%$ & $50 \%$ \\
\hline & & 75 & $100 \%$ & $100 \%$ & $75 \%$ \\
\hline
\end{tabular}


Table 2: Percentages of participants in each group who made a correct keep/refer decision for all vignettes within each category.

\begin{tabular}{lccc} 
& \multicolumn{2}{c}{ Musculoskeletal } & \multicolumn{2}{c}{ Medical non critical } & Medical critical \\
\cline { 2 - 4 } & \multicolumn{1}{c}{ Yes } & Yes & Yes \\
\cline { 2 - 4 } Intervention group & $91.4 \%$ & $75.9 \%$ & $1.7 \%$ \\
Control group & $98.3 \%$ & $63.8 \%$ & $3.4 \%$
\end{tabular}

\section{Appendix 1}

Were you generally satisfied with the intervention (lecture)?

Yes $\bigcirc$

No $\bigcirc$

Cannot say $\bigcirc$

Do you personally feel that the additional lecture was helpful for you to make an accurate keep/refer decision (based on the 11 vignettes)?

Yes

No

Unsure $\bigcirc$

Do you personally feel that the intervention (lecture) was too time consuming? Yes $\bigcirc$

No $\bigcirc$

Cannot say $\bigcirc$ 
